\title{
Erratum to: Immortalized bovine pancreatic duct cells become tumorigenic after transfection with mutant k-ras
}

\author{
Matthias Löhr • Petra Müller • Ira Zauner • \\ Christian Schmidt • Birgit Trautmann • \\ Frank Thévenod • Gabriel Capellá • Antonio Farré • \\ Stefan Liebe $\cdot$ Ralf Jesenofsky
}

Published online: 23 March 2012

(C) Springer-Verlag 2012

Erratum to: Virchows Arch (2003) 438:581-590

DOI 10.1007/s004280100397

The author name listed as "Ralf Jesnowski," has been changed to "Ralf Jesenofsky"

The online version of the original article can be found at http://dx.doi. org/10.1007/s004280100397.

M. Löhr $(\varangle)$

Department of Medicine IV, Molecular Gastroenterology,

Medical Faculty of Mannheim, University of Heidelberg,

Theodor-Kutzer-Ufer 1-3,

68135 Mannheim, Germany

e-mail: matthias.loehr@med4.ma.uni-heidelberg.de

M. Löhr · P. Müller $\cdot$ C. Schmidt $\cdot$ S. Liebe $\cdot$ R. Jesenofsky

Department of Medicine, University of Rostock,

Rostock, Germany

I. Zauner $\cdot$ B. Trautmann

Department of Medicine I, University of Erlangen-Nuremberg,

Erlangen, Germany

F. Thévenod

Department of Physiology, University of Saarland,

Bad Homburg, Germany

G. Capellá · A. Farré

Laboratori d'Investigacio Gastrointestinal, Institut de Recerca,

Hospital de Sant Pau, Universita Autonoma,

Barcelona, Spain 